\title{
Does Motivation to Migrate Matter? Voluntary and Forced African Migrants and Their Acculturation Preferences in New Zealand
}

\author{
Martine Udahemuka and Regina Pernice \\ Massey University, New Zealand
}

\begin{abstract}
$A s$ there is no research on forced migration of African migrants to New Zealand, in particular on Athe interrelations among psychological motives to migrate and psychological acculturation preferences, the present study aims to address this gap. One hundred and five forced and voluntary African migrants to New Zealand completed a questionnaire, which included two measures (a) the Psychological Motives to Migrate (Tharmaseelan, 2005) and (b) the Psychological Acculturation Index (Mace, 2004). Demographic information, including data on the New Zealand government immigration categories through which the migrant gained entry and length of time in New Zealand, was also collected. Multivariate analyses indicated that motivations to migrate do matter when it comes to acculturation preferences. Further, it was found that psychological motives to migrate were better predictors of acculturation preferences than the government immigration categories. Specifically, voluntary migrants (those motivated by 'family life improvement' and 'exploration') preferred to adapt to New Zealand culture, while forced migrants (those motivated by 'escaping') had a higher preference to maintain their culture of origin. Duration of time in New Zealand was correlated with acculturation preferences. Implications of the findings point to the importance of assessing motivations to migrate from a psychological perspective.
\end{abstract}

Keywords: African refugees, African migrants, African acculturation, Africans in New Zealand, asylum seeker, migration motivation, humanitarian, migration choice

The movement of people (voluntary and forced) across borders is an international phenomenon and usually driven by either economic need or social reasons (Knipscheer \& Kleber, 2007). In New Zealand, the changes to immigration policies since the late 1980s resulted in a rapid increase in numbers of highly skilled migrants (Winkelmann, 2001). Large proportions of skilled migrants have come from China and India, and since the early 1990s an increasing number of Africans have chosen to migrate to New Zealand.

By 2006, African migrants originated from at least forty-four countries and they entered New Zealand via different pathways. The voluntary immigrants usually come to New Zealand under the skilled migrant category (Walrond, 2007). In addition, a small number came voluntarily as students or visitors and were later approved for permanent residency (Merwood, 2007). The forced African migrants such as refugees, asylum seekers and family quota refugees were resettled under the humanitarian immigration category in New Zealand, the majority due to the wars in Somalia, Sudan, the Congo, Burundi and the genocide in Rwanda.

Evidently, the African migrant population in $\mathrm{New}$ Zealand includes individuals whose migration experiences differed significantly in terms of choice or motives to migrate. As there is no research on forced African migrants and their acculturation to New Zealand, this study investigates the interrelations among the motivation to migrate, the New Zealand government immigration categories and psychological acculturation for these migrants.

\section{Motivation to Migrate}

Migration research has proposed two main factors that are generally evident in the motives that lead migrants to leave their country of origin, namely, pull and push 
factors (Kunz, 1973, Ward, Bochner, \& Furnham, 2001). Kunz suggested that the motivations for migration are either a result of being pushed out of one's country or being pulled towards another country. His main focus was on distinguishing between the various types of refugees (anticipatory or acute) whereas Ward et al. (2001) focused on factors contributing to voluntary migration and proposed that immigrants are pulled or attracted towards the new country in pursuit of personal, familial, social, financial and/or political goals.

The reduction of the possible range of psychological motivations to migrate down to just two factors (either push or pull) may be too simplistic and recent research findings suggested that both factors could be present. Pernice, Trlin, Henderson, North, and Skinner (2009) found in their study, which compared the mental health and employment status of skilled Indian, Chinese and South African voluntary migrants to New Zealand, that the South Africans reported both pull and push factors concomitantly. They had been attracted to New Zealand for its culture, climate and lifestyle, but they also had felt pushed to leave South Africa due to its political instability, violence and crime. These push forces seemed to have superseded the pull forces which 'do not appear to have as much weight in their decision to migrate as the push forces' (p. 27).

Other researchers have investigated the range of psychological factors that motivated people to either migrate to or emigrate from New Zealand (Carr, Inkson, \& Thorn, 2005; Jackson et al., 2005; Tharmaseelan, 2005). Carr et al. (2005) factor analysed the motives that contributed to business expatriates' decisions to stay abroad or to come back to New Zealand and identified political, family, economic, culture, lifestyle and career advancement as the main factors. In her study on Sri Lankan migrants in New Zealand, Tharmaseelan (2005) identified a similar variety of motives for migrating to those found by Carr et al. (2005). Consequently, these differences in motivations to migrate may also translate into different migration outcomes such as acculturation.

\section{Acculturation}

One of the most extensively theorised and researched psychological phenomenon in global mobility is the concept of acculturation (for example Berry, 1990; Berry, 2006; Berry, Kim, Power, Young, \& Bujaki, 1989; Nesdale \& Mak, 2000; Ward \& Kennedy, 1994). The term acculturation refers to cultural changes that result from prolonged and direct contact between two distinct cultural groups (Berry, 2005). Psychologically adjusting to a new culture results in changes to the immigrant's values, behaviours and beliefs towards the host country and this process has been shown to have a direct link with migration outcomes such as stress and wellbeing and/or sociocultural outcomes such as finding employment (Berry, 2001; Mace, Atkins, Fletcher, \& Carr, 2005; Sam, Vedder, Ward, \& Horenczyk, 2006; Tharmaseelan, 2005).
Berry $(1980 ; 1990)$ proposed the Quadri-Modal Acculturation Model based on two fundamental issues to the acculturation process and the intercultural contact for migrants: (1) the maintenance of the culture of origin and (2) the maintenance and relationships with members of the host society. Four acculturation styles can result from this interaction and may be derived from a combination of the yes and no answers to (a) do you consider it to be of value to maintain ties with your own culture? and (b) do you consider it of value to maintain ties with the culture of the host country? Migrants can then be grouped into an integration, assimilation, separation or marginalisation style. The integration style is assumed when individuals maintain their culture of origin but also adapt to the culture of the host society, assimilation is the adaptation to the host society's culture and the rejection of the culture of origin, separationists reject the culture of the host society and maintain only their culture of origin and marginalisation refers to the rejection of both cultures (Berry, 1997).

In support of Berry's conceptualisation, a number of research findings suggested that generally migrants prefer the integration style, followed by the assimilation style (Ward et al., 2001; Ward \& Kennedy, 1994). Moreover, research on the migrants' acculturation outcomes provided evidence that preferences for integration and separation were related to more positive outcomes while assimilation and marginalisation were associated with negative adjustment outcomes (Berry, 2005; Berry, 1986; Berry, Kim, Minde, \& Mok, 1987; Ward, 2006). Particularly, integration has been shown to be a better predictor of positive outcomes, including social adjustment, greater life satisfaction and reduced psychological and sociocultural adaptation problems (Berry, 2006).

However, operationally defining psychological acculturation using the four acculturation styles by reducing multiple psychological items down to four categories implies a possible loss of information in the process (Sang \& Ward, 2006; Ward, 1999). An alternative method of deriving acculturation styles is the use of an acculturation index. Generally, measures of acculturation strategies employ an index to assess preferences of behaviour in a number of public and private life domains (e.g., language use, food, dress and religious practices) using two similar or identical statements, for example, I prefer to dress like they do in my home country and I prefer to dress like they do in my host country. This type of index has received support as it makes use of the two independent subscales to represent the culture of origin and the host culture dimensions and, in turn, using the scores on the two dimensions individuals can also be categorised into one of the four acculturation styles (Sang \& Ward, 2006; Ward \& Kennedy, 1994; Ward \& Rana-Deuba, 1999). In addition, the use of scores on each of the two subscales may be better predictors of acculturation outcomes than the four strategies, especially if there is reason to believe that the index is measuring two independent 
dimensions. Further, the use of independent dimensions has allowed some researchers to investigate whether each dimension may be predicted by different factors, such as the motives or reasons to migrate (Mace et al., 2005; Porter, 2006; Tharmaseelan, 2005).

\section{Linking Motives to Migrate and Acculturation}

Previous researchers have provided important knowledge to the migration literature with regards to the differences in the way migrants negotiate the ongoing intercultural contact in the new society depending on their reasons for migration (Cobb-Clark, 2000; Horgan, 2000; Knipscheer, De Jong, Kleber, \& Lamptey, 2000; Kunz, 1973; Petersen, 1958; Tharmaseelan, 2005). Knipscheer et al. (2000) assessed motivations to migrate, in terms of push and pull and their acculturation consequences. The researchers found that Ghanaian migrants in the Netherlands who were pulled towards the host country were more adapted to the Netherlands, compared to the migrants who had been pushed out of Ghana for varied reasons. Similarly, Horgan (2000) found that reasons to migrate were related to acculturation styles. Horgan quantitatively examined the differences between government migration categories (refugees and international students) in Ireland and their acculturation style preferences and found a similar relationship to that identified by Knipscheer et al. (2000). Refugees were more likely to be integrationists, which is a preference to maintain the culture of origin and to adapt to the host culture, while there was a tendency by international students to want to assimilate, which refers to high preference to adapt to the host culture.

Horgan (2000) explained that it may be that refugees seek to hold on to their culture as much as they can since they did not 'choose' to leave their country, but at the same time they realise that since their migration is likely to be a permanent move they would also benefit by learning and adapting to the culture of the host country. On the other hand, the international students, knowing that their stay in Ireland would be temporary and that they would go back to their home country, desired to absorb and learn as much of the Irish culture as they could in that period; hence the reason for choosing assimilation as an acculturation style.

A considerable limitation of Horgan's (2000) study is that it failed to acknowledge that measuring motives to migrate only on the basis of governmental migration categories may not necessarily capture the complex psychological motives, which influence the final decision to migrate. Further, Horgan's comparison was between heterogeneous groups, as the refugees were all from Africa, while the international students were predominantly from Europe, with only two Somalis and one Argentinean in this category. These subsamples of participants are quite likely to differ in their cultural values in the first instance; therefore, comparing their acculturation preferences may have been problematic. One

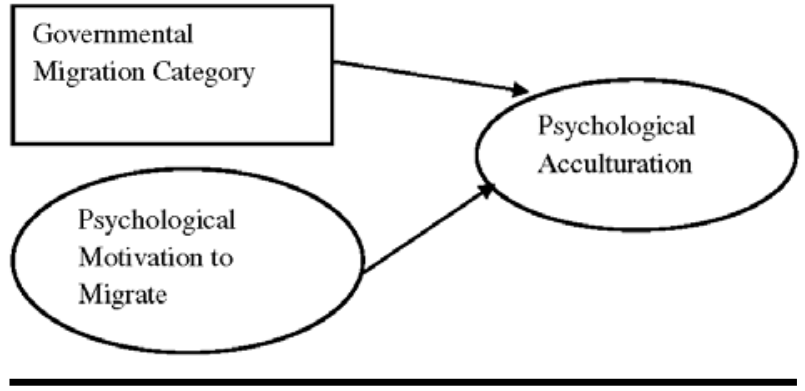

Figure 1

An exploratory model of the motives to migrate and acculturation for African migrants in New Zealand.

may question whether the findings are not actually a result of the comparison of the acculturation preferences between African and European migrants.

Contrary to Horgan's findings, Porter (2006) carried out a qualitative investigation into the acculturation preferences of 37 South Africans in New Zealand and found that those who preferred to assimilate were more likely to have migrated predominantly for reasons of escaping from war and crime, while those who were integrationists were mostly motivated to migrate due to better employment prospects and wanting to provide an education for their children.

Although the findings are inconsistent, they have provided a stepping stone for a model with these two concepts to be tested for new migrant populations. From Figure 1, the proposed model aims to test the predicted links between the motives to migrate and acculturation preferences (using two operational definitions) for forced and voluntary African migrants to New Zealand. As no study has previously investigated forced and voluntary African migrants and their acculturation preferences in New Zealand, it was hypothesised that (1) forced migration will be related to integration while voluntary migration will be related to assimilation and (2) psychological motives to migrate will be better predictors of acculturation preferences than the New Zealand government migration categories; specifically the migrants with more choice in their migration decision will prefer to adapt to the New Zealand culture, while those with less choice will prefer to maintain their culture of origin.

\section{Method \\ Participants}

One hundred and five African migrants who live permanently in New Zealand completed a self-report questionnaire for the study. There were 50 females and 55 males aged between 18 and 59 years of age, $(M=$ $34.75, S D=10.59)$ who had been in New Zealand on average 6 years $(S D=3.37)$. Four people did not specify their age. 
The respondents originated from twelve African countries: Zimbabwe $(n=38)$, South Africa $(n=16)$, Rwanda $(n=11)$, Burundi $(n=10)$, Kenya $(n=6)$, Ghana $(n=4)$, Zambia $(n=5)$, Uganda $(n=3)$, Somalia $(n=3)$, Congo $(n=2)$, Egypt $(n=1)$ and Ethiopia $(n=$ $1)$. Five people did not state their country of origin.

\section{Materials}

Psychological acculturation. Acculturation preferences were measured with Mace's (2004) Acculturation Index adapted for our novel sample. This index included two scales containing items representing the culture of origin and those representing the mainstream New Zealand culture. The participants had to indicate how much of the time they preferred to keep practices/behaviours from their own culture in comparison to adapting to practices/behaviours from the mainstream New Zealand culture on a scale of 1 (never/not relevant) to 5 (always). Further, in order to categorise participants' preferences into one of Berry's (1980) four acculturation styles, the median split method was used. The categorisation depended on where each individual score was in relation to each index subscale's median score.

Psychological motivation to migrate. The motivation to migrate variable was assessed using a measure adapted from Tharmaseelan (2005). She developed this measure, based upon a literature review and informal discussions with subject matter experts, to assess the migration reasons of Sri Lankan migrants in New Zealand. Tharmaseelan performed a confirmatory factor analysis and found five factors: financial betterment, family building, escaping, exploration and career building. The instrument was reliable with all the components having $\alpha$ values above 0.75 . The measure comprised 24 items assessing possible reasons that might motivate a person to migrate from one place to another. The participants were asked to indicate how much each of the items influenced their reasons to migrate to New Zealand on a scale of 1 (not at all/not relevant) to 5 (very much).

Demographics. In addition to the measures described above, self-report data on the respondent's gender, age, country of origin, highest qualification, language, government immigration category of entry to New Zealand and length of time in New Zealand were collected (see Udahemuka, 2008).

\section{Procedure}

A pilot study was conducted and revisions were made following feedback. The data collection procedure followed a snowballing technique. This sampling technique uses personal contacts to identify and recruit more participants from their own networks (Langdridge, 2004; Porter, 2006).

The first stage involved identifying participants from the first author's personal contacts and networks of people who fit the selection criteria and then giving them questionnaire packages either personally or by post. Participants also supplied contact details of potential participants from their own network or were given extra questionnaire packages to distribute to their contacts.

Secondly, settlement services agencies and societies including the Manawatu African Society and the Auckland Refugee and Migrant Service were approached personally to assist in the distribution of the questionnaires to their members.

Thirdly, participants were identified and recruited through community-organised events throughout the year; these included, for example, the annual soccer tournament, concerts, and other social functions that brought numbers of Africans together. The research was approved by the Massey University Human Ethics Committee in 2007.

\section{Results \\ Preliminary Analysis}

Migration status. Respondents came to New Zealand under the government immigration category: Skilled migrant $(n=45)$, visitor $(n=16)$, student $(n=6)$, family reunification $(n=11)$, family quota $(n=11)$, refugee $(n$ $=12$ ), asylum seeker $(n=3)$ and business $(n=1)$. In terms of choice level, a migrant who entered New Zealand under the skilled category is not distinguished from one who migrated under the business category; therefore, both were combined with the student and visitor categories and labelled 'voluntary' $(n=68)$. Likewise, those who came as refugees, asylum seekers or under the family quota were grouped into the 'forced' immigration category $(n=26)$. These two groups reflect one of the operational definitions of migration motivation based on the level of individual choice, the alternative being the psychological motives to migrate. The family reunification participants were excluded from further analyses as they could not clearly be classified as either voluntary or forced.

Psychological motives to migrate. The 24-item measure had a Kaiser-Meyer-Oklin (KMO) value of .80 and a significant Bartlett's test of sphericity (869.68, $d f=105, p<$ .001). Seven items were removed based on details from the scree plot, communalities and reliability analyses. Thereafter, a clear four-component structure was evident. From Table 1, the first component in the final solution was labelled 'exploration' with 5 items loading highly on it. The second component was labelled 'improving family life' and was represented by 5 highly loading items. The third factor 'escaping' had 3 highly loading items; and, lastly, the fourth component named 'financial betterment' had 4 items. The Cronbach's alphas for the four components ranged from .80 to .91 .

Psychological acculturation. The measure of sampling adequacy revealed a KMO value of .72 and a significant Bartlett's test of sphericity $(870, d f=253, p<.001)$. 
Based upon acculturation literature, which proposes the presence of two components, one relating to 'maintenance of home culture' and the other to 'adapting to host culture', a two-component factor was extracted. From Table 2, a solution with the two proposed components was evident. Eleven items loaded strongly on the 'maintain culture of origin' component, while 13 loaded strongly on the 'adapt to New Zealand culture' component. Items that decreased the scales' internal consistency substantially were removed. The Cronbach's alphas for the subscales were moderate at .79 for adapting to New Zealand culture and acceptable at .68 for the maintenance of the culture of origin components.

To determine which acculturation style individual respondents preferred, the median split method was used (Arends-Tóth \& van de Vijver, 2006). A scatter plot revealed a close to normal distribution of the two component average scores, which is a requirement for the use of the median split method. Respondents were categorised in an acculturation style depending on where their scores were in relation to the median on each component.

Psychological acculturation was thus measured in two ways. On the one hand, acculturation preferences were coded as individual average scores on each component representing both acculturation dimensions. On the other hand, individuals were grouped into one of the four acculturation styles. Thus, one operational definition of psychological acculturation (acculturation style) was more abstract than the other (component score). Both were used in subsequent analyses.

\section{Main Analysis}

Migration status and acculturation. First, a two by four contingency table was created to test a hypothesised link between government immigration category and acculturation style. A chi-square test did not reveal any significant evidence of association between immigration category (voluntary or forced) and acculturation style $\chi^{2}$ $(3, N=80)=.82, n s$.

Secondly, using the alternative acculturation definition based on dimension scores, a MANCOVA was used. Once the means had been corrected for the effects of duration of time in New Zealand, it was noticeable that the forced migrants, on average, had higher preferences to maintain their culture of origin compared with the voluntary migrants. A similar trend was observed when the means were unadjusted.

The MANCOVA results revealed that duration of time in New Zealand significantly predicted $20 \%$ of the variance in acculturation scores $F(2,74)=9.51, p<$ .0001 . However, once the effect of time in New Zealand was taken out, the main effects of immigration category were not significant, Wilk's Lambda $F(2,74)=2.52, p>$ .05 , partial eta squared $=.7$.

Overall, the MANCOVA and chi-square results revealed no evidence linking government immigration category with either of the two ways of measuring acculturation (dimensions and styles). This finding indicates

\section{Table 1}

Psychological Motives to Migrate Measure Rotated Component Matrix

\begin{tabular}{|c|c|c|c|c|}
\hline Items & Exploration & Improving family life & Escaping & Financial betterment \\
\hline Seeing new things & .89 & & & \\
\hline Visiting places & .86 & & & \\
\hline Seeing the world & .85 & & & \\
\hline Visiting different countries & .84 & & & \\
\hline To live in different environment & .72 & & & \\
\hline To improve the children's life & & .86 & & \\
\hline For the children's education & & .85 & & \\
\hline Felt could learn something in NZ & & .74 & & \\
\hline Quality of life & & .67 & & .33 \\
\hline Political situation & & & .84 & \\
\hline Victim of war & & & .83 & \\
\hline Ethnic conflict & & & .80 & \\
\hline Money & & & & .85 \\
\hline Salary & .31 & & & .77 \\
\hline Financial & & & & .77 \\
\hline Variance (\%) & 24.95 & 18.12 & 15.34 & 14.96 \\
\hline Total variance (\%) & & & & 73.40 \\
\hline Eigenvalues & 5.40 & 2.70 & 1.67 & 1.23 \\
\hline Alphas & .91 & .84 & .82 & .80 \\
\hline
\end{tabular}

Note: Extraction Method: Principal Component Analysis. Rotation Method: Varimax with Kaiser Normalization. Rotation converged in 5 iterations. Eigenvalues over 1 were extracted. Loadings $<.3$ were suppressed. 
Table 2

Psychological Acculturation Index Rotated Component Matrixa

\begin{tabular}{|c|c|c|}
\hline Items & $\begin{array}{l}\text { Adapt to New } \\
\text { Zealand culture }\end{array}$ & $\begin{array}{l}\text { Maintain culture } \\
\text { of origin }\end{array}$ \\
\hline Job opportunities (NZ) & .74 & \\
\hline Look for jobs (NZ) & .73 & \\
\hline Friends (NZ) & .72 & \\
\hline Recreational activities (NZ) & .71 & \\
\hline Job interviews (NZ) & .70 & \\
\hline Food (NZ) & .52 & \\
\hline Language at home (NZ) & .49 & \\
\hline Cultural events/activities (NZ) & .48 & -.33 \\
\hline Identity (NZ) & .48 & -.46 \\
\hline Clothing (NZ) & .47 & \\
\hline Religious beliefs (NZ) & .43 & \\
\hline Values (NZ) & .39 & -.36 \\
\hline Identity (Home) & & .68 \\
\hline Values (Home) & & .65 \\
\hline Food (Home) & & .64 \\
\hline Recreational activities (Home) & & .63 \\
\hline Friends (Home) & .31 & .61 \\
\hline Cultural events/activities (Home) & & .58 \\
\hline Language used at home (Home) & & .58 \\
\hline Language outside of home (Home) & & .54 \\
\hline Job opportunities (Home) & & .57 \\
\hline Clothing (Home) & & .53 \\
\hline Beliefs (Home) & & .46 \\
\hline Eigenvalues & 4.99 & 4.07 \\
\hline Total variance (\%) & & 39.41 \\
\hline Variance (\%) & 20.02 & 19.34 \\
\hline
\end{tabular}

Note: Extraction Method: Principal Component Analysis. Rotation Method: Varimax with Kaiser Normalization. ${ }^{\text {a }} .2$ Components extracted. Eigenvalues over 1 were extracted. Loadings $<.3$ were suppressed.

that the underlying psychological motives may be better predictors of acculturation preferences.

Psychological motives to migrate and acculturation. Hierarchical regressions were carried out, one for each acculturation dimension. For both variables 'maintain culture of origin' and 'adapt to New Zealand culture', the duration of time in New Zealand variable was controlled for in step 1, and then the psychological motives were entered as a block in step 2. The predictor variables were entered in the model as blocks to investigate how much variance, as a measure, the psychological motives predicted of one global construct (i.e. acculturation).

In the first hierarchical analysis, with home culture as the dependent variable, duration of time in New Zealand significantly explained $9 \%$ of the variance in maintaining culture of origin scores, $F(1,90)=10.02, p<.01$. Psychological motives predicted $7 \%$ of the variance when duration of time in New Zealand was held constant, but the finding was not significant, $F$-change $(4,83)=1.73, p$ $>.05$. The whole model significantly predicted $16.7 \%$ of the variance, $F(5,83)=3.33, p<.01$.
The second regression was computed with the 'adapt to New Zealand culture' variable. Eight per cent of the variance in levels of adapting to New Zealand culture was explained by the duration of time in New Zealand, $F$ $(1,86)=7.44, p<.01$. The psychological motives to migrate significantly explained an extra $12 \%$ of variance over and above that explained by duration of time in New Zealand, $F(4,82)=3.06$, sig. change $p<.05)$. The full model with all the variables included explained $20 \%$ variance, $F(5,82)=4.08, p<.001$.

Thus, the psychological motives significantly explained some variance in psychological acculturation, specifically for the levels of adapting to New Zealand culture. Given that the predictive ability of the psychological motives as a group was ascertained, to test the unique contribution of individual psychological motivation components, each of the five components were entered in the model individually starting from the variable (based on the literature) thought to have a weaker relationship with adapting to New Zealand (e.g., escaping) and ending with exploration motives as the variable was thought to have a greater link with the dependent variable. To control for the variable, duration of time in New Zealand was entered in the first step. The same procedure was performed for the 'maintain culture of origin' component. Duration of time in New Zealand ( $\beta .283$, $p$ $<.5)$, exploration $(\beta .218, p<.01)$ and improving family life $(\beta .284, p<.05)$ components positively and uniquely contributed to the variance in the scores on the adapting to New Zealand culture component. The beta values suggest that, with each unit increase in each of the three significant predictors, there is a unit increase in the preference to adapt to the New Zealand culture. The regression model with 'maintain culture of origin' revealed that 'escaping' has a unique and significant contribution to the variance in the dependent variable. See Figure 2 for an illustration of the significant relationships with corresponding beta weights.

\section{Discussion}

This study investigated the interrelationship among motivations to migrate, government immigration category and acculturation preferences of voluntary and forced African migrants to New Zealand. Given that recruitment relied on a snowballing method that resulted in a small sample of African migrants to New Zealand $(N=105)$ and particularly in a very small subsample of forced migrants $(n=26)$, the findings need to be considered with appropriate caution. The main finding of the research was as expected: psychological motives to migrate were better predictors of acculturation preferences than government migration categories, even when the effects of length of time in New Zealand were taken into account. Time in New Zealand, adventure and family variables all significantly and uniquely explained some variance in the 'adapt to New Zealand 


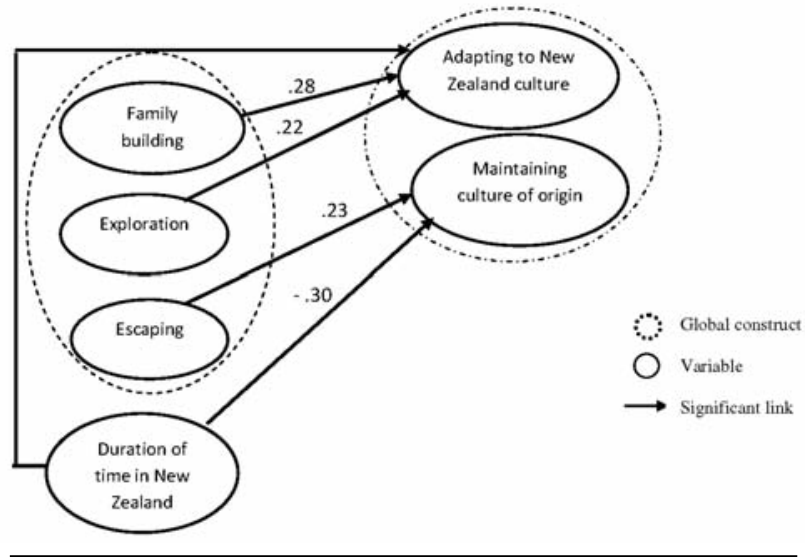

Figure 2

Resultant model with significant relationships.

culture' scores, while the motivation to escape predicted home culture maintenance scores.

The first hypothesis suggested that government immigration category (forced or voluntary) would predict psychological acculturation preferences. This hypothesis was based on Horgan's (2000) findings that refugees (forced) had a preference for integration compared to international students (voluntary) migrants who preferred to assimilate with the Irish culture. In the present study, however, acculturation preferences were not predicted by government immigration category; hence Horgan's findings were not supported by the present study of African participants.

An explanation for this finding might be that, while one can speculate on what the migrants' motives are, based on the government immigration category under which they entered New Zealand, these categories do not necessarily capture the underlying motivations that lead migrants to come to New Zealand. One of the criteria for entering New Zealand under a refugee immigration category is that one must be temporarily in exile (temporarily living outside his/her country of origin). This criterion may put pressure on an individual, who may want to migrate for reasons of persecution for example, but who is still residing in the country of origin. The individual might try and find other avenues of entering into a country, perhaps as a skilled migrant or on a visitor or student visa. Clearly, for some, the government immigration category might serve as a means to an end, but provides little information about the underlying motivation for their migration. Hence the second hypothesis that the psychological motives to migrate provide more information on the way African migrants handle the intercultural contact once they are in New Zealand than the government immigration category.

The second hypothesis that psychological motives to migrate would be linked to acculturation preferences was supported. The relationship between these two concepts remained significant even when the effect of duration of time in New Zealand was taken into account. Specifically, migrants whose main motives to migrate were related to providing a better life for their family and to explore New Zealand had high preferences to adapt to New Zealand culture. On the contrary, migrants whose migration was motivated by a need to escape from their home country preferred to maintain ties with their culture of origin. These findings suggest that the former groups of migrants - those who had high preferences of adaption to the New Zealand culture - were attracted to New Zealand and had chosen it, and therefore would want to immerse themselves into the local lifestyle. The latter group - those migrants who moved for reasons of escaping - conceptually have had much less choice in their decision to leave their country, and thus would want to hold on to their culture as much as they possibly could.

Moreover, the finding that the escaping migrants preferred to maintain their culture of origin, while the more voluntary migrants preferred to adapt to New Zealand culture, can be related back to Kunz's (1973) conceptualisation of the differences between anticipatory and acute migrants. The circumstances for those migrants who would have left their home to escape might not have given them a chance to prepare for their migration journey and to get used to the idea of leaving their country permanently. Therefore, these acute refugees might want to hold onto elements of their culture for as long as they can. Voluntary migrants, those motivated by opportunities to improve their family life, may have anticipated their migration and therefore be more prepared and determined to succeed by adapting to New Zealand culture.

In their study, Ourasse and van de Vijver (2005) suggested that prior knowledge of the host society and fluency in the host country language have been linked to higher levels of acculturation with the culture of the host society. This may be the case for migrants who were pulled by the desire to explore New Zealand and for those who wanted to provide better opportunities for their family and, in particular, their children.

The findings are in contrast with those reported by Porter (2006), where the South Africans who provided predominantly escaping type reasons for their migration preferred an assimilation style (adaptation to New Zealand culture), while integration was preferred by those whose main motives to migrate were related to the attraction of New Zealand for different reasons and building a future for their children. One reason that may explain Porter's results might be that her South African participants were all of European descent, while the majority of the participants in the present research were Black Africans. Culturally, these two groups of migrants are vastly disparate; therefore, one may not necessarily expect their acculturation preferences to be the same on the basis of their motivation to migrate. The lack of data on ethnicity is a limitation of this study; 
however, calls are made for future research to build on the findings while addressing this shortcoming.

\section{Future Research Directions}

Research has rarely compared empirical evidence between forced and voluntary migrants, even less within the African migration community in New Zealand. Future researchers should be encouraged to investigate the relationship between motivation to migrate and acculturation with a larger sample to account for the diversity among the African migrants. Moreover, there is lack of evidence on outcomes of generational comparison. Future studies could investigate differences between generations to find out whether those who came as children experience the ongoing intercultural contact differently from their parents.

\section{Conclusion}

International migration is characterised by mixed migration motivations. Individuals can be classified into migration groups based on their immigration category, that is, forced or voluntary. The former process represents a migration motivated both by the imperative of flight from violence and unliveable conditions, while the latter is motivated by lifestyle preferences and economic gains. The present study has shown that these different motivations matter postmigration. Specifically, the migrants assumed to have high levels of choice in their migration had a higher preference to adapt to the New Zealand culture compared with those with less choice who had a preference to maintain the culture of origin. This study can provide a basis for future researchers to investigate ways in which to enhance and encourage integration within migrant groups. The findings may also help inform future policy development and service provision concerned with forced and voluntary African migrants.

\section{Acknowledgments}

The findings reported in this article are based on Martine Udahemuka's thesis (2008) submitted in partial fulfilment of the requirements for the degree of Masters of Arts in Psychology at Massey University, New Zealand. Many thanks to Professor Stuart Carr whose invaluable guidance throughout the thesis journey made a substantial difference. Thank you to the kind participants who took part in the research, without you, the study would not have been possible.

\section{References}

Arends-Tóth, J.V., \& van de Vijver, F.J.R. (2006). Assessment of psychological acculturation: Choices in designing an instrument. In D.L. Sam \& J.W. Berry (Eds.), Handbook of acculturation psychology (pp. 142-160). Cambridge, UK: Cambridge University Press.

Berry, J.W. (1980). Acculturation as varieties of adaptation. In A. Padilla (Ed.), Acculturation: Theory, models and findings (pp. 9-25). Boulder, CO: West-view.
Berry, J.W. (1984). Multicultural policy in Canada: A social psychological analysis. Canadian Journal of Behavioural Sciences, 16(4), 353-370.

Berry, J.W. (1986). Acculturation and psychological adaptation: A conceptual overview. In J.W. Berry \& R.C. Annis (Eds.), Ethnic psychology: Research and practice with immigrants, refugees, native peoples, ethnic groups and sojourners (pp. 41-53). Amsterdam: Swets \& Zeitlinger.

Berry, J.W. (1990). Psychology of acculturation. In J. Berman (Ed.), Cross-cultural perspectives: Nebraska symposium on motivation (pp. 201-234). Lincoln, NE: University of Nebraska Press.

Berry, J.W. (1997). Immigration, acculturation and adaptation. Applied Psychology: An International Review, 46(1), 5-68.

Berry, J.W. (2001). A psychology of immigration. Journal of Social Issues, 57(3), 615-631.

Berry, J.W. (2005). Acculturation: Living successfully in two cultures. International Journal of Intercultural Relations, 29(6), 697-712.

Berry, J.W. (2006). Contexts of acculturation. In D.L. Sam \& J.W. Berry (Eds.), The Cambridge handbook of acculturation psychology (pp. 27-42). New York: Cambridge University Press.

Berry, J.W., Kim, U., Minde, T., \& Mok, D. (1987). Comparative studies of acculturative stress. International Migration Review, 21(3), 491-511.

Berry, J.W., Kim, U., Power, S., Young, M., \& Bujaki, M. (1989). Acculturation attitudes in plural societies. Applied Psychology, 38, 185-206.

Carr, S.C., Inkson, K., \& Thorn, K. (2005). From global careers to talent flow: Reinterpreting 'brain drain'. Journal of World Business, 40, 386-398.

Cobb-Clark, D.A. (2000). Do selection criteria make a difference? Visa category and the labour market status of immigrants to Australia. Economic Record, 76(232), 15-31.

Horgan, O. (2000). Seeking refuge in Ireland: Acculturation stress and perceived discrimination. In M. MacLachlan \& M. O'Connell (Eds.), Cultivating pluralism: Psychological, social and cultural perspectives on a changing Ireland (pp. 60-85). Dublin, Ireland: Oak Tree Press.

Jackson, D., Carr, S.C., Edwards, M., Thorn, K.J., Allfree, N., Hooks, J., et al. (2005). Exploring the dynamics of New Zealand's talent flow. New Zealand Journal of Psychology, 34(2), 110-116.

Knipscheer, J.W., De Jong, E.E.M., Kleber, R.J., \& Lamptey, E. (2000). Ghanaian migrants in The Netherlands: General health, acculturative stress and utilization of mental health care. Journal of Community Psychology, 28(4), 459-476.

Knipscheer, J.W., \& Kleber, J. (2007). Acculturation and mental health among Ghanaians in the Netherlands. International Journal of Social Psychiatry, 53(4), 369-383.

Kunz, E.F. (1973). The refugee flight: Kinetic models and forms of displacement. International Migration Review, 7(2), 125-146.

Langdridge, D. (2004). Introduction to research methods and data analysis in psychology. Harlow, UK: Pearson Education Ltd. 
Mace, K.A. (2004). Psycho-social correlates of employment amongst skilled newcomers to New Zealand. Unpublished master's thesis, Massey University, Auckland, New Zealand.

Mace, K.A., Atkins, S., Fletcher, R., \& Carr, S.C. (2005). Immigrant job hunting, labour market experiences, and feelings about occupational satisfaction in New Zealand: An exploratory study. New Zealand Journal of Psychology, 34(2), 97.

Merwood, P. (2007). International students: Studying and staying on in New Zealand, Department of Labour. Retrieved February 5, 2009, from http://www.dol.govt.nz/ publication-view.asp? $\mathrm{ID}=235$

Nesdale, D., \& Mak, A.S. (2000). Immigrant acculturation attitudes and host country identification. Journal of Community and Applied Social Psychology, 10(6), 483-498.

Ourasse, O.A., \& van de Vijver, F.J.R. (2005). The role of demographic variables and acculturation attitudes in predicting sociocultural and psychological adaptation in Moroccans in the Netherlands. International Journal of Intercultural Relations, 30(3), 251-272.

Pernice, R., Trlin, A., Henderson, A., North, N., \& Skinner, M. (2009). Employment status, duration of residence and mental health among skilled migrants to New Zealand: Results of a longitudinal study. International Journal of Social Psychiatry, 55(3), 272-287.

Petersen, W. (1958). A general typology of migration. Journal of Sociology, 23(3), 256-266.

Porter, S.A. (2006). Highly skilled South African immigrants in New Zealand. Unpublished master's thesis. Massey University, Auckland, New Zealand.

Sam, D., Vedder, P., Ward, C., \& Horenczyk, G. (2006). Psychological and sociocultural adaptation. In J.W. Berry, J. Phinney, D. Sam, \& P. Vedder (Eds.), Immigrant youth in cultural transition: Acculturation, identity and adaptation across national contexts. Hillsdale, NJ: Lawrence Erlbaum.

Sang, D.L., \& Ward, C. (2006). Acculturation in Australia and New Zealand. In D. Sam \& J.W. Berry (Eds.). The Cambridge handbook of acculturation psychology (pp. 253-272). Cambridge: Cambridge University Press.

Tharmaseelan, N. (2005). Careers in cross-cultural context: A study of Sri Lankan immigrants in New Zealand. Unpublished doctoral dissertation, Massey University, Auckland, New Zealand.

Udahemuka, M. (2008). The motivation to migrate, acculturation, and finding employment: The case of African migrants in New Zealand. Unpublished master's thesis, Massey University, Palmerston North, New Zealand.

Ward, C. (2006). Acculturation, identity and adaptation in dual heritage adolescents. International Journal of Intercultural Relations, 30(2), 243-259.

Ward, C., Bochner, S., \& Furnham, A. (2001). The psychology of culture shock (2nd ed.). Hove, UK: Routledge.

Ward, C., \& Kennedy, A. (1994). Acculturation strategies, psychological adjustment and sociocultural competence during cross-cultural transitions. International Journal of Intercultural Relations, 18(3), 329-343.

Ward, C., \& Rana-Deuba, A. (1999). Acculturation and adaptation revisited. Journal of Cross-Cultural Psychology, 30(4), 372-392.

Walrond, C. (2007). 'Africans', Te Ara-the encyclopaedia of New Zealand, updated. Retrieved March 10, 2008, from http://www.TeAra.govt.nz/NewZealanders/NewZealand Peoples/Africans/en

Winkelmann, R. (2001). Immigration policies and their impact: The case of New Zealand and Australia. In S. Djaji (Ed.), International migration: Trends, policies, and economic impact (pp. 1-20). London: Routledge. 